This item was submitted to Loughborough's Research Repository by the author.

Items in Figshare are protected by copyright, with all rights reserved, unless otherwise indicated.

\title{
Network behaviours, social capital, and organisational learning in high- growth entrepreneurial firms
}

PLEASE CITE THE PUBLISHED VERSION

https://doi.org/10.1504/IJESB.2011.039006

\section{PUBLISHER}

(C) Inderscience

\section{VERSION}

AM (Accepted Manuscript)

\section{PUBLISHER STATEMENT}

This work is made available according to the conditions of the Creative Commons Attribution-NonCommercialNoDerivatives 4.0 International (CC BY-NC-ND 4.0) licence. Full details of this licence are available at: https://creativecommons.org/licenses/by-nc-nd/4.0/

\section{LICENCE}

CC BY-NC-ND 4.0

\section{REPOSITORY RECORD}

Hughes, Mathew, Robert E. Morgan, R. Duane Ireland, and Paul Hughes. 2019. "Network Behaviours, Social Capital, and Organisational Learning in High-growth Entrepreneurial Firms". figshare.

https://hdl.handle.net/2134/26370. 


\title{
Network behaviors, Social Capital, \& Organizational Learning in High-Growth Entrepreneurial Firms
}

Submitted to: International Journal of Entrepreneurship and Small Business (Special Issue edited

by Fredric Kropp)

\author{
Mathew Hughes ${ }^{\dagger}$ \\ Nottingham University Business School \\ Robert E. Morgan \\ Cardiff University \\ R. Duane Ireland \\ Texas A\&M University \\ Paul Hughes \\ Loughborough University
}

Dr. Mathew Hughes (corresponding author) ${ }^{\dagger}$, Nottingham University Business School, University of Nottingham, Jubilee Campus, Wollaton Road, Nottingham NG8 1BB, United Kingdom. Tel: +44 115 8467747. Fax: +44 115 8466650. E-mail:

mat.hughes@nottingham.ac.uk.

Dr. Robert E. Morgan, Cardiff University, Cardiff Business School, Colum Drive, Cardiff CF10 3EU, United Kingdom. Tel: +44 292087 0001. Fax: +44 292087 4419. E-

mail: morganre@cardiff.ac.uk.

Dr. R. Duane Ireland, Texas A\&M University, Mays Business School, 4113 TAMU, College Station, Texas 77843-4113, USA. Tel: 979862 3963. Fax: 979845 9641. E-mail:

direland@mays.tamu.edu.

Dr. Paul Hughes, Loughborough University, The Business School, Loughborough, Leicestershire LE11 3TU, United Kingdom. Tel: +44 1509 228274. Fax: +44 1509 223962. Email:p.hughes@lboro.ac.uk

Acknowledgement: The authors would like to thank United Kingdom Business Incubation (UKBI) for their support in the data generation phase of this study. Support provided by John Cadogan is also appreciated. A previous version of this manuscript was presented at the XIII Academy of Marketing Science World Marketing Congress. We thank the participants at the conference for their valuable comments and feedback, which aided in the development of this work. 


\section{Author Biographies}

Mathew Hughes is an Associate Professor in Entrepreneurship \& Innovation at Nottingham University Business School. His research interests include entrepreneurial orientation, learning, networking and social capital. His research appears in such journals as Industrial Marketing Management, British Journal of Management and Journal of Business Research.

Robert E. Morgan is Associate Dean and the Sir Julian Hodge Professor of Marketing and Strategy at Cardiff Business School, Cardiff University. His main research interests include market-based organizational learning, strategic alliance management, and strategic entrepreneurship. His publications number over 90, and he has consulted widely with international firms and government departments on these issues.

R. Duane Ireland holds the Foreman R. and Ruby S. Bennett Chair in Business in the Mays Business School, Texas A\&M University. Prior to joining Texas A\&M University in 2004, he held the W. David Robbins Chair in Strategic Management in the Robins School of Business, University of Richmond, and before that, the Curtis Hankamer Chair in Entrepreneurship in Baylor University's Hankamer School of Business. He is the co-author of more than a dozen scholarly books and textbooks, including two recently released books, Entrepreneurship: Successfully Launching New Ventures and Understanding Business Strategy, and the $7^{\text {th }}$ edition of Strategic Management: Competitiveness and Globalization. He is the author or co-author of more than 70 journal articles. His work has been published in a number of journals including AMJ, AMR, SMJ, ASQ, AME, Journal of Management Studies, Decision Sciences, Human Relations, and Long Range Planning. Duane has received numerous awards for his teaching and research. A Fellow of the Academy of Management, he is currently serving Editor for Academy of Management Journal.

Paul Hughes is a Lecturer in Strategic Management at Loughborough University Business School. His current research interests include (i) the marketing-strategy interface; (ii) the strategic management process within organizations with respect to product-market strategy; (iii) information processing and information use in organizations; (iv) adherence to strategy; (v) the strategic outcomes associated with product-market strategy and (vi) strategic failure. 


\title{
Network behaviors, Social Capital, \& Organizational Learning in High-Growth Entrepreneurial Firms
}

\begin{abstract}
Despite recent conceptual and theoretical insights into social capital, little is known about the behaviors that generate social capital and how social capital influences organizational learning. The difficulty this gap creates for young entrepreneurial firms is that their managers understand little about how to strategically develop firm behavior in an effort to create social capital, which is expected to be a powerful means for such firms to overcome their liabilities of newness. Adopting a business incubation context, we present data from a census of UK business incubatees testing relationships among network behaviors (resource sharing, shared beliefs, tolerance of incubator management, and strategic network participation), social capital (localized and externalized), and organizational learning (accelerated learning and knowledge assimilation). We find that network behaviors have contrasting effects in generating localized and externalized social capital and both types of social capital differentially influence accelerated learning and knowledge assimilation.
\end{abstract}

Key-words: Knowledge assimilation; learning; network behavior; social capital. 
Business incubation research suffers a dearth of conceptual and empirical study. As such, we know little about how business incubators aid young high-technology firms to create value. Extant research has focused on business incubation as a strategic network (Hansen, Chesbrough, Nohria, \& Sull, 2000; Kambil, Eselius, \& Monteiro, 2000). This theoretical heritage forms the basis of our definition of a business incubator as a hub to which incubating firms are connected and external organizations are brought in to provide business assistance or opportunities to collaborate. As such, an incubator is a networked community of firms. Hansen et al. (2000) claim incubating firms can only create value from business incubation when the incubation system reflects a network configuration. Kambil et al. (2000) extend this idea by positing how active involvement in the incubator community can inspire firms to collaborate in ways that generate social capital, the outcome of which is proposed to be superior learning.

The intersection of network factors, social capital, and learning is poorly understood despite the importance attached to social interactions in firm learning (Nahapiet \& Ghoshal, 1998). This problem is exacerbated by the tendency in network research to view organizational learning in terms of knowledge acquisition. Yet, organizational learning only confers advantage when a firm is able to generate, assimilate, transform, and exploit knowledge (Fiol \& Lyles, 1985; Schulz, 2001). Firms thus need processes to transform knowledge into learning outcomes. Social capital is proposed to result from the network behaviors firms develop with those around them as creating social capital itself requires firms to interact continuously within strategically managed relationships (Yli-Renko, Autio, \& Sapienza, 2001). Research on strategic networks has, for the most part, examined network structure and content as opposed to network behavior. Consequently, our understanding of the antecedents and consequences of social capital remains scant in both theoretical and empirical terms. Studies have tended to ignore network behavior or treat it as haphazard interaction. Given that social capital is defined on the basis of 
interaction(s), addressing this gap in research will help develop new insight into the ways in which firms can interact strategically to create value.

Our research questions are: (1) what network behaviors generate social capital? (2) what forms do social capital take? and, (3) what influence do network behaviors and social capital have on organizational learning?

\section{THEORETICAL FRAMEWORK}

The success rate of incubation programs in the U.S. is estimated to be $87 \%$ (Hackett \& Dilts, 2004). The U.K. has a similar rate of $84 \%$. Both compare favorably with the failure rate of non-incubated firms at near 90\% (Peters, Rice, \& Sundararajan, 2004). Yet despite such statistics, we know very little about the mechanisms that lead these firms to succeed.

The purpose of business incubation is to imbue young firms with opportunities to learn to rapidly leverage its knowledge base and so overcome liabilities of newness. The opportunity for incubating firms to learn is said to be optimized when the incubator structure reflects a network configuration (Hansen et al., 2000). This implies a structure in which the incubator is a central hub to which a portfolio of incubating firms are connected and to which a host of external partners are connected. We call this the incubator network. External organizations include public bodies that offer business services (sometimes on site), consultants, and private companies that are invited to join the network by incubator management (Hansen et al., 2000). An incubator network presents opportunities for resource exchange, collaboration, timely assistance, and knowledge synergy that in turn facilitate organizational learning (Hughes, Ireland, \& Morgan, 2007).

Kambil et al. (2000) posit that incubating firms can only extract value from incubation when social capital is high. Social capital research supports this view (Nahapiet \& Ghoshal, 1998). Our framework herein is drawn from social capital theory (Nahapiet \& Ghoshal, 1998) 
and embeddedness theory (Andersson, Forsgren, \& Holm, 2002). A firm is not independent of its social system. Its actions with other firms in the social network generate social capital, a goodwill credential that is developed by the incubating firm through its actions over time with other firms, affecting the conditions necessary for value creation. As interaction with networked firms grows, the firm increases its embeddedness in the social network which exposes it to greater quantity and richer quality of knowledge. The firm experiences considerable opportunities to learn as its social capital grows yet its ability to learn is governed by the firm's processes, as set out in learning theory. By managing its network behavior to synthesize social capital, its exposure to knowledge and the learning programs of other firms presents opportunities to improve its own learning programs. But, the extent to which social capital is created regulates such opportunity. Value cannot accrue from presence within a network alone; it depends on how firms interact within the incubator network or else opportunities to learn will remain unrealized (Hughes et al., 2007).

Network behavior can be defined as different behavioral strategies employed by firms to manage their interaction with other firms in the incubator network. Such behavior alters the nature of any relationship a firm can build and maintain. Poor management of such behavior likely damages the creation of social capital and later learning. The most crucial form of network behavior is those that emphasize close strategic interaction among firms. We frame our choice of behaviors on the fact that the strategic behavior of firms in networks is typically oriented towards learning (Hagedoorn \& Duysters, 2002). Motivated by liabilities of newness, firms seek out resources and knowledge, so, their behaviors are aimed at synthesizing close interaction with others. In an incubator network, firms are motivated to share resources reciprocally to enable them to pursue joint projects (Hansen et al., 2000); to develop shared beliefs to exploit symbiosis among firms (Kambil et al., 2000); to participate widely in the network community to share knowledge on competitive tactics and models (Kambil et al., 2000); and, to tolerate and allow 
incubator managers to connect disparate firms with one another to exploit synergies or share knowledge further (Rice, 2002). These behaviors establish an interface between incubating firms and the system of networked firms that mobilize interaction.

We define resource sharing as the exchange or co-produced recombination of resources, tangible or intangible, undertaken to create value. Resource sharing can develop complementary advantages among firms by accessing and bundling resources into new combinations. Shared beliefs with respect to incubating entrepreneurial firms are formed around to share a sense of innovativeness, entrepreneurship, and exploration among firms to inform the manner in which collaboration should take. Shared beliefs determine the nature of cooperation (Kogut, 2000). Kambil et al. (2000) posited that firms develop shared beliefs to catalyze entrepreneurial abilities. Tolerance for incubator management is defined as the extent to which help by incubator management teams is tolerated by incubating firms (Rice, 2002). Strategic network participation is the extent to which firms seek out interaction and seek out the involvement of networked firms in business activities and thereby purposely pursuing partnerships with other firms. The extent to which participation is 'active' influences the outcomes a firm can build from network relationships (Hughes et al., 2007; Lane \& Lubatkin, 1998). Social capital is the ability of actors to secure benefits by virtue of their relationships within networks and can be thought of as the strength of relations among firms that unlocks value (Nahapiet \& Ghoshal, 1998). We differ from most treatments of social capital by proposing that it is not unidimensional. Rather, we propose that depending on the locus of network relationships the firm is embedded in, social capital is bidimensional in turn.

We argue there are two levels to the relationships in an incubator network-(1) relationships between incubating firms (local network), and (2) relationships between incubating firms and partner organizations affiliated with the incubator (external network). Just as the locus 
of the network relationship can differ, we propose that social capital in this incubator network is similarly multilayered. We suggest that the nature of the relationships among incubating firms (local network) differs compared to the relationships between an incubating firm and external network partners (external network) but are synthesized from similar behaviors. We use the term localized social capital to express the strength and quality of the relationships between incubating firms. We use the term externalized social capital to express the strength and quality of the relationships between an incubating firm and external network members. Both reflect the embeddedness of the firm in these different networks of ties (e.g., Andersson et al., 2002).

We follow Fiol \& Lyles (1985) to define organizational learning as the process of improving actions through better knowledge and understanding. As such, knowledge entering the firm needs to go through a process of transformation to generate learning. This process can be augmented by accelerated learning and improvement in knowledge assimilation. Accelerated learning we define as an increase in the speed at which knowledge is obtained, processed, and transformed into outcomes. Knowledge assimilation captures the ability of a firm to digest, adapt, and apply knowledge in the firm to integrate learning outcomes (Zahra \& George, 2002).

\section{HYPOTHESES}

It is rare for a single firm to possess all resources necessary to outperform competitors. Thus, insufficient resource stocks is a chief motivation for interfirm interaction as opportunities to share complementary resources can help firms meet new market opportunities or address competitive threats. The willingness to actively participate in resource sharing encourages close interaction and enduring relations between an incubating firm and the collaborative partner, be they another incubating firm or an external network member. Firms develop an awareness of each other's resources in initial interactions which then spur collaboration based on resource sharing. By sharing resources, firms are able to undertake projects they could not successfully pursue 
alone. Joint projects may create value, which stimulates the growth of social capital (Chung, Singh, \& Lee, 2000). These relationships develop reciprocally and as firms develop stronger interactive ties, more social capital should be created as the firm becomes more embedded.

Hypothesis 1: Resource sharing is related positively to (a) localized social capital and (b) externalized social capital.

Shared beliefs define cooperation among firms. These beliefs also set the parameters of the network community as they define its social nature. Like-mindedness encourages closer and more dynamic interaction between firms. Although such compatibility is likely to be greater between localized incubating firms as the cognitive distance between them is likely to be lower (for example, they face similar challenges from liabilities of newness and the need to explore market possibilities), it is still possible to have shared beliefs between incubating firms and external members of the incubator network due to the common interest created by the entrepreneurial imperative (e.g., Henderson, 1999). Shared beliefs facilitate synergy among cooperating firms by encouraging the leveraging of common abilities in pursuit of common interests. Kogut (2000) alludes to such interaction leading to closer relationship ties and Kambil et al. (2000) theorized that social capital should result from such synergistic interaction.

Hypothesis 2: Shared beliefs are related positively to (a) localized social capital and (b) externalized social capital.

Incubator managers can affect the activities of incubating firms to offer targeted assistance or identify potential collaborators to help incubating firms reduce weaknesses and manage threats (Rice, 2002). Short-term competitiveness issues often distract young firms causing them to be myopic to collaborative opportunities. Because of this tendency, incubating firms should be receptive to the coordination and signposting of incubator managers. Tolerance of incubator management helps firms to understand problems by allowing a third party independent of the biases of the firm's managers to direct the firm to others to co-produce 
solutions. Incubator managers can essentially help firms bridge gaps in their networks. Young firms often lack understanding of their difficulties and how they can be resolved. Incubator management can help identify problems and match the firm with another incubating firm or external networked firms to help resolve problems. But, it depends on the firm's tolerance for it. Such interaction can spur greater collaboration opportunities that improve the basis for knowledge sharing (Dyer \& Nobeoka, 2000). This implies that such tolerance is a catalyst to strengthening network ties as the firm becomes further embedded in the network. In turn, the social capital at the heart of the network should increase.

Hypothesis 3: Tolerance for incubator management is related positively to (a) localized social capital and (b) externalized social capital.

The propensity to participate in networks is often influenced by a firm's time, needs, knowledge of other organizations, and its willingness to bring potential partners into its business activities. Participation builds embeddedness. A firm's embeddedness in a network of ties is important to securing valuable benefits because it enables social capital (McEvily \& Zaheer, 1999), but the actual degree of participative behavior governs social capital and how it might release value. Active participation is necessary to spur social capital because it signals to peers, at both network levels, that a firm wishes to cooperate and develop reciprocal relations. This reflects an eagerness to involve others while promoting openness and enthusiasm.

Hypothesis 4: Strategic network participation is related positively to (a) localized social capital and (b) externalized social capital.

Firms do not exist independent of social contexts and firms in one community can influence the evolution of other communities of firms. Through interaction, firms can co-evolve and co-develop social capital. As incubating firms cooperate and collaborate, the localized social capital generated should help legitimize the partnering firm with others in the external network with which the initial firm had developed relations, and vice-versa. Thus, localized social capital 
should have a positive effect on externalized social capital by increasing awareness of the cooperative capacity of an incubating firm. Increased awareness and exposure should help the firm develop a broader web of external relationships.

Hypothesis 5: Localized social capital is related positively to externalized social capital.

Different degrees of network behavior have been associated with distinctive patterns of exposure to knowledge which in part result from leveraging networking opportunities that pose unique circumstance-specific advantages (McEvily \& Zaheer, 1999). Network resources have been associated with greater learning opportunities (Gulati, 1999). Firms able to access, explore, and exploit complementary resources through networks can realize improvements in learning. Also, resource complementarity tends to reduce overlap between firms’ knowledge sets resulting in more significant opportunities to learn. Resource sharing whereby firms continuously pool, experiment, and exploit resources and knowledge will lead to increased understanding of their collaborative and competitive use, thereby accelerating learning.

Hypothesis 6: Resource sharing is related positively to accelerated learning.

Firms that actively participate in a range of network relationships are predicted to experience greater organizational learning as the extent to which a firm can learn has been associated with repeated, intense interaction (Lane \& Lubatkin, 1998). Firms have distinctive capacities to learn and assimilate outcomes resulting from knowledge searches. Creating connections to knowledge sources and developing close relationships with different partners has been associated with improvements in knowledge stocks and the ability to assimilate information (Lane \& Lubatkin, 1998). However, linkages alone are insufficient to explain how improvements occur because linkages could lie dormant. As each firm maintains idiosyncratic patterns of active network linkages, a firm is then differentially exposed to new knowledge and to firms that can help it understand, interpret and assimilate new knowledge (McEvily \& Zaheer, 1999). Active 
strategic network participation can strengthen a firm’s knowledge assimilation because repeated, intense interactions increase the idiosyncratic exposure of the firm to different types of knowledge and different interpretations of its meaning and relevance. Over time, this would be expected to facilitate a firm’s ability to independently discover learning outcomes from knowledge by expanding its interpretation, assimilation, and ability to apply knowledge.

Hypothesis 7: Strategic network participation is related positively to knowledge assimilation.

A networking strategy emphasizing intensive repeated interaction through active collaboration within a strategic network of firms can facilitate superior learning (Dyer \& Nobeoka, 2000; Lane \& Lubtakin, 1998). We would expect that social capital, representing the strength, quality and embeddedness of relations, will dictate the richness of knowledge unlocked and so, learning.

Knowledge possessed by firms at the localized level will be different to that possessed by firms at the externalized level as each firm is a repository of valuable knowledge and each has a different locus of knowledge. Incubating firms at the localized level will be more in tune with the problems encountered by young firms and so can address managerial and competitive difficulties these firms might share. Incumbent firms in the externalized network possess a substantial degree of knowledge on strategic and competitive issues that are of significant value to incubating firms. Rich interaction between firms at these levels can create social capital that catalyzes accelerated learning (Kambil et al., 2000). High social capital requires reciprocity which encourages firms to share knowledge regarding competitive information, approaches, tactics, models, and common mistakes thereby rapidly expanding the knowledge base of incubating firms. Owing to the close that is associated with superior stocks of social capital, social capital can facilitate faster interpretation and analysis of information to quickly create new knowledge meaningful to the 
firm. Findings by Schulz (2001) support this argument: close networking facilitates faster and more comprehensive discovery of the meaning of knowledge. So, irrespective of its locus, greater social capital should improve organizational learning.

Social capital affects the conditions necessary for the exchange and combination of intellectual resources (Nahapiet \& Ghoshal, 1998), such as access, disclosure, exploitation, and integration (Yli-Renko et al., 2001). However, exploiting knowledge requires that it is assimilated into the firm for learning to become permanent. Social capital should lead to a strengthening of a firm's knowledge assimialtion because it encourages broader access, integration, and analysis of knowledge through contributions from firms held in close relations. Localized incubating firms and externalized network partners can increase the learning processes of an incubating firm by broadening its thinking, promoting critical analysis of knowledge, and aiding the interpretation of knowledge.

Hypothesis 8: Localized social capital is related positively to accelerated learning. Hypothesis 9: Externalized social capital is related positively to knowledge assimilation. Hypothesis 10: Externalized social capital is related positively to accelerated learning. Hypothesis 11: Localized social capital is related positively to knowledge assimilation.

\section{METHODS}

We used the United Kingdom Business Incubation (UKBI) directory of business incubators as our sampling frame as inclusion in the directory required incubation programs to have a network in place. We screened this directory to ensure we only sampled high-technology incubating firms. Of the 196 incubators initially identified, 143 catered for high-technology firms exclusively. We then randomly sampled the 143 incubator facilities and sampled their portfolio of incubating firms until a database of 1,000 incubating firms was obtained. Exploratory interviews identified the Managing Director as the most relevant informant. We established that multiple informants would not improve the quality of data as these single informants exhibited 
exclusively a wide knowledge of the business and its processes. It was also clear that acquiring multiple respondents would be extremely prejudicial to securing the cooperation of these firms with the survey. Accordingly, a single informant design was used.

We pre-tested the survey with groups that could offer expert insight into content validity and face validity. Academic researchers with expertise in entrepreneurship, organizational learning, and small firm development were consulted. We also consulted senior personnel at UKBI, regional development agencies, and other non-governmental organizations. Several amendments were made based on suggestions for improving the survey instrument. We then administered a mail survey to our sample. Pre-notification correspondence, a questionnaire and information package, and a series of follow-up reminders were sent to sampling units. We used questionnaire salience, length, return postage, anonymity and confidentiality guarantees, university sponsorship, UKBI endorsement, and respondent incentives to aid response rate. Response rate was 21\%. We tested for non-response bias (Armstrong \& Overton, 1977) and found no significant differences $(p<.05)$ between early and late respondents.

We adapted existing scales and developed some new measures (Table 1). We measured: resource sharing (Cronbach $\alpha=.90$ ) with items drawn from Sarkar, Echambadi, Cavusgil, \& Aulakh (2001); shared beliefs ( $\alpha=.94)$ with items developed using Kambil et al. (2000); tolerance for incubator management ( $\alpha=.81)$ with items drawing on Rice (2002); strategic network participation ( $\alpha=$.74) with items developed by McEvily \& Zaheer (1999); localized social capital $(\alpha=.95)$ and externalized social capital $(\alpha=.93)$ with modified scales from Andersson et al. (2002) using Hansen et al. (2000), Kambil et al. (2000) and others; accelerated learning ( $\alpha=$.96) using Sarkar et al. (2001); and, knowledge assimilation $(\alpha=.81)$ using work by Calantone, Cavusgil, \& Zhao (2002). We used 7-point Likert scales for all measures ranging from "strongly disagree" (1) to "strongly agree” (7). 
We used the Harman one-factor test to assess common method variance (Podsakoff $\&$ Organ, 1986). A principal components analysis of all measures produced a six factor solution with eigenvalues greater than 1.00 and total explained variance of $78 \%$. As several factors were extracted, the first factor accounted for only $17 \%$ of total variance, and no general factor was extracted from the unrotated factor structure, common method bias was not considered to be an obstacle to further analysis. We examined the scales using confirmatory factor analysis (CFA). Using LISREL8 we estimated a single measurement model. The CFA $\left(\chi^{2}=471.68\right.$, d.f. $=278, p$ $<.001)$ resulted in good fit to the data $(\mathrm{CFI}=.98 ; \mathrm{TLI}=.98$; $\mathrm{RMSEA}=.05)$. Each item loaded significantly $(p<.01)$ onto the specified construct (ranging from .61 to .95) and the average variance extracted ranged from .53 to .88 , satisfying the $50 \%$ cut-off suggested by Fornell \& Larker (1981) to claim convergent validity. The alpha coefficients reported earlier and the composite reliabilities all exceed the .70 level of acceptable reliability (Fornell \& Larker, 1981).

\section{[Insert Table 1 about here]}

\section{RESULTS}

Hypotheses were tested using path analysis in LISREL8 (Table 2). The fit is excellent, suggesting that the proposed model fits the data well $\left(\chi^{2}=465.96\right.$, d.f. $=271, p<.001 ;$ CFI $=.98$, $\mathrm{TLI}=.98$; RMSEA $=.05) .9$ of the 15 paths are statistically significant and in the anticipated direction indicating support for hypotheses H1a, H3a, H4a-H7, H10, H11. Three hypotheses were not statistically significant: shared beliefs $\rightarrow$ localized social capital (H2a: $\gamma=-.03, t=-.41$ ), tolerance for incubator management $\rightarrow$ externalized social capital (H3b: $\gamma=.09, t=1.29$ ), and localized social capital $\rightarrow$ accelerated learning (H8: $\gamma=.01, t=.14$ ). Three hypotheses were refuted: resourcing $\rightarrow$ externalized social capital (H1b: $\gamma=-.21, t=-2.05$ ), shared 
beliefs $\rightarrow$ externalized social capital (H2b: $\gamma=-.17, t=-2.69$ ), and externalized social capital $\rightarrow$ knowledge assimilation (H7: $\beta=-.29, t=-1.90)$.

\section{[Insert Table 2 about here]}

\section{DISCUSSION \& CONCLUSIONS}

We identify network behaviors that influence social capital and demonstrate that social capital is not universal but operates at different levels taking different forms. We show that network behavior and social capital have contrasting influences on firm learning. The results are mixed; evidence that our cumulative understanding of these constructs is underdeveloped.

Network behavior is found to be an antecedent to social capital. Ad hoc behavior in strategic networks is not a viable approach for firms if they wish to accrue improvements in their learning. Firms must plan a network behavior strategy to generate localized and externalized social capital. Active participation is the most important of the behaviors suggesting the need for firms to be extrovert and open in their cooperative strategies. Tolerance for incubator management had a positive influence on both social capital types, implying that firms should demonstrate a willingness to accept and initiate interventionist behavior.

Against our expectations, despite generating a strong effect on localized social capital, resource sharing had a negative influence on externalized social capital. This points to a strategic complementarity issue and implies that to optimize the benefits of resource sharing, firms should focus on localized relationships with like firms. The negative relationship with externalized social capital is likely caused by lack of strategic compatibility in the firms' collective resource portfolios. If we consider firms to be bundles of resources, large differences might complicate interaction between firms, which in turn can be expected to retard social capital. 
Shared beliefs also contradicted expectations demonstrating a negative influence on both types of social capital, albeit non-significant on localized social capital. It was expected that shared beliefs would help stimulate more dynamic interaction among firms, but this is not the case. This might be explained by risk theory. Shared beliefs are intertwined with risk brought about by the uncertainty of opportunity-seeking behavior. The prevailing uncertainty causes firms to hold tentative or hesitant relationships that are not conductive to building social capital. An interaction strategy must balance this apparent relational dynamic therefore.

Our findings demonstrate that social capital is a more complex phenomenon than so far presented and so we contribute to its theoretical and empirical development. We show that social capital not only operates at two different levels in strategic networks but also that localized social capital positively influences externalized social capital. Localized social capital grants access to contact webs that enhance externalized social capital. In effect, localized social capital works as a legitimizing mechanism that facilitates the introduction of a firm to other external networked organizations. A cooperative strategy tactically using a localized social web can improve external links and so externalized social capital. An eclectic cooperative strategy should account for the behaviors that optimize localized social capital prior to maximizing externalized social capital.

Investing in social capital carries significant learning rewards. However, our findings show contrasting effects. Localized social capital was found to influence knowledge assimiation whereas externalized social capital influenced accelerated learning positively but negatively affected knowledge assimilation. These findings present strategic choice implications for optimizing learning outcomes from social interactions. Externalized network relationships should be built and maintained for the purposes of accelerating learning. Established organizations have a broad knowledge bank and thus a young firm can benefit greatly from their expansive locus of knowledge if it forms dedicated relationships with them. However, the findings suggest that 
localized relationships alone should be used for the purposes of augmenting knowledge assimilation. A reason for this difference lies in the likelihood that incubating firms share common grounds. As a result, their locus of interpretation is more in tune with the needs and problems of each other. Externalized social capital negatively affects knowledge assimilation because the locus of interpretation is likely beyond the scope of the incubating firm.

Our final two hypotheses proposed that resource sharing would positively influence accelerated learning and strategic network participation would positively knowledge assimilation. These were supported. Resource sharing enhances the basis for experimentation and exploitation which accelerates learning. Strategic network participation facilitates development of knowledge assimilation as active participation helps broaden the interpretive horizon of the firm through exposure to new ideas and new ways of thinking. Network behavior can be used strategically to exploit social capital to develop learning in pursuit of competitive advantage.

There are limitations to our study. First, our findings can only be generalized to the incubator network context although we suspect they may have broader relevance. Second, our model is tested on young high-technology incubating firms only and so we cannot generalize whether these same relationships will hold true for other types of firms. Third, we contribute to understanding of social capital in terms of learning advantages but we do not examine the influence network behaviors might have on social capital's other proposed outcomes.

Several directions for future research emerge from our work. First, we need greater understanding of network behavior. Ad hoc network behavior is insufficient as not all behaviors prove positive despite their perceived value. More knowledge is needed of how firms can behave strategically in networks to tailor social capital and learning. Second, social capital was found to be different under different contexts and a strategy that clearly identifies which social capital is to be manipulated and how will have a marked effect on learning. Research is needed to establish 
whether alternative forms of social capital produce yet more contrasting outcomes. Third, we provided evidence of how network behavior and social capital influence accelerated learning and knowledge assimilation. Our study suggests that these two components have potential and realized levels. Future research should examine intra-firm and inter-firm conditions that augment these features of learning. Finally, this study has demonstrated that incubation networks should promote strategic principles if young firms are to maximize outcomes. Our understanding of incubation is incomplete and inconclusive since few conceptual and empirical studies exist. 


\section{REFERENCES}

Andersson, U., Forsgren, M., and Holm, U. (2002) 'The strategic impact of external networks: Subsidiary performance and competence development in the multinational corporation', Strategic Management Journal, Vol. 23, pp.979-996.

Armstrong, J.S. and Overton, T.S. (1977) 'Estimating non-response bias in mail surveys', Journal of Marketing Research, Vol. 14, pp.396-402.

Calantone, R.J., Cavusgil, S.T., and Zhao, Y. (2002) 'Learning orientation, firm innovation capability, and firm performance’, Industrial Marketing Management, Vol. 31, pp.515-524.

Chung, S., Singh, H. and Lee, K. (2000) 'Complementarity, status similarity, and social capital as drivers of alliance formation', Strategic Management Journal, Vol. 21, pp.1-22.

Dyer, J.H. and Nobeoka, K. (2000) 'Creating and managing a high-performance knowledgesharing network: The Toyota case’, Strategic Management Journal, Vol. 21, pp.345-367.

Fiol, C.M. and Lyles, M.A. (1985) 'Organizational Learning', Academy of Management Review, Vol. 10, pp.803-813.

Fornell, C. and Larker, D.F. (1981) 'Evaluating structural equation models with unobservable variables and measurement error', Journal of Marketing Research, Vol. 18, No. 2, pp.39-50.

Gulati, R. (1999) 'Network location and learning: The influence of network resources and firm capabilities on alliance formation', Strategic Management Journal, Vol. 20, pp.397-420.

Hackett, S.M. and Dilts, D.M. (2004) 'A systematic review of business incubation research', Journal of Technology Transfer, Vol. 29, pp.55-82.

Hagedoorn, J. and Duysters, G. (2002) 'Learning in dynamic inter-firm networks: The efficacy of multiple contacts’, Organization Studies, Vol. 23, No. 4, pp.525-548.

Hansen, M.T., Chesbrough, H.W., Nohria, N., and Sull, D.N. (2000) 'Networked incubators: Hothouses of the new economy', Harvard Business Review, Vol. 78, No. 5, pp.74-84.

Henderson, A. (1999) ' Firm strategy and age dependence: A contingent view of the liabilities of newness, adolescence, and obsolescence’, Administrative Science Quarterly, Vol. 44, No. 2, pp.281 - 324.

Hughes, M., Ireland, R.D., and Morgan, R.E. (2007) 'Stimulating dynamic value: Social capital and business incubation as a pathway to competitive success', Long Range Planning, Vol. 40, No. 2, pp.154-177.

Kambil, A., Eselius, E.D., and Monteiro, K.A. (2000) 'Fast venturing: The quick way to start web businesses', Sloan Management Review, Vol. 41, No. 4, pp.55-67.

Kogut, B. (2000) 'The network as knowledge: Generative rules and the emergence of structure', Strategic Management Journal, Vol. 21, pp.405-425.

Lane, P.J. and Lubatkin, M. (1998) 'Relative absorptive capacity and inter-organizational learning’, Strategic Management Journal, Vol. 19, pp.461-477. 
McEvily, B. and Zaheer, A. (1999) 'Bridging ties: A source of firm heterogeneity in competitive capabilities’, Strategic Management Journal, Vol. 20, pp.1133-1156.

Nahapiet, J. and Ghoshal, S. (1998) 'Social capital, intellectual capital, and the organizational advantage’, Academy of Management Review, Vol. 23, pp.242-266.

Peters, L., Rice, M., and Sundararajan, M. (2004) 'The role of incubators in the entrepreneurial process’, Journal of Technology Transfer, Vol. 29, pp.83-91.

Podsakoff, P.M. and Organ, D.W. (1986) 'Self-reports in organizational research: Problems and prospects’, Journal of Management, Vol. 21, pp.913-929.

Rice, M.P. (2002) 'Co-production of business assistance in business incubators: An exploratory study’, Journal of Business Venturing, Vol. 17, pp.163-187.

Sarkar, M., Echambadi, R., Cavusgil, S.T., and Aulakh, P.S. (2001) 'The influence of complementarity, compatibility, and relationship capital on alliance performance', Journal of the Academy of Marketing Science, Vol. 29, pp.358-373.

Schulz, M. (2001) 'The uncertain relevance of newness: Organizational learning and knowledge flows’, Academy of Management Journal, Vol. 44, pp.661-681.

Yli-Renko, H., Autio, E., and Sapienza, H.J. (2001) 'Social capital, knowledge acquisition, and knowledge exploitation in young technology-based firms', Strategic Management Journal, Vol. 22, pp.587-613.

Zahra, S.A. and George, G. (2002) 'Absorptive capacity: A review, re-conceptualization, and extension’, Academy of Management Review, Vol. 27, 185-200. 
TABLE 1

Confirmatory Factor Analysis Results of Measures

Measures Item Description

Standardized $t$-Value

Factor Loading

Resource Sharing $\left(\mathrm{CR}^{\mathrm{a}}=.91, \mathrm{AVE}^{\mathrm{a}}=.78\right)$

Inputs brought into the incubator by each participant are valuable for each

.81 other

Participants provide vital inputs we find difficult to obtain elsewhere

Participants share a level of mutual dependence to achieve stronger competitive performance

15.20

Shared Beliefs $(\mathrm{CR}=.94$, AVE $=.80)$

A creative and vibrant atmosphere exists within the incubator

Businesses in the incubator share a common feeling of creativity

.85

.93

.94

.88

The incubator generates a creative environment to explore and experiment

Tolerance for Incubator Management $(\mathrm{CR}=.81$, AVE $=.59)$

Incubator management often intervene (sometimes expectedly and unexpectedly) to provide our business with different forms of assistance

Incubator management often intervene 'out-of-the-blue' to help our business to identify difficulties and solve problems

Intervention by incubator management has been useful in solving problems in our business

Strategic Network Participation $(\mathrm{CR}=.78, \mathrm{AVE}=.64)$

We find it necessary to involve ourselves in a business network

We try to bring many participants into our business processes and projects early

Localized Social Capital $(\mathrm{CR}=.96, \mathrm{AVE}=.85)$

Relationships with incubator businesses are important to our ability to compete

Relationships with incubator businesses have been important in helping our business to grow

Relationships with incubator businesses has led to changes in how we conduct our business

Our relationships with incubator businesses are important to our business activities

Externalized Social Capital (CR $=.94$, AVE $=.85)$

Relationships with business network members are important to the growth of our business

Relationships with business network members has led to changes in how we conduct our business

Our relationships with network members are important to our business

Accelerated Learning ( $\mathrm{CR}=.96, \mathrm{AVE}=.88$,

Our rate of learning is far ahead of where we would be had we 'gone it alone'

Operating in this incubator has provided a fast way of learning

The quality of knowledge and experiences gained are superior than had we 'gone it alone' 
Lessons learned from past product/project/business decisions are thoroughly analyzed and shared with others in the business lessons learned from history

${ }^{\mathrm{a}} \mathrm{CR}=$ composite reliability. AVE = average variance extracted.

${ }^{\mathrm{b}}$ Item fixed to set the scale.

TABLE 2

Path Estimates

\begin{tabular}{|c|c|c|c|c|c|c|}
\hline \multicolumn{2}{|c|}{ Hypothesis } & \multicolumn{2}{|c|}{ Path } & \multirow{2}{*}{$\begin{array}{c}\begin{array}{c}\text { Hypothesized } \\
\text { Relationship }\end{array} \\
+\end{array}$} & \multirow{2}{*}{$\begin{array}{c}\begin{array}{c}\text { Standardized } \\
\text { Path Estimate }\end{array} \\
.59\end{array}$} & \multirow{2}{*}{$\begin{array}{r}t \text {-Value }^{\mathrm{a}} \\
6.62^{* *}\end{array}$} \\
\hline H1a: & Resource sharing & $\rightarrow$ & Localized social capital & & & \\
\hline H1b: & Resource sharing & & $\begin{array}{l}\text { Externalized social } \\
\text { capital }\end{array}$ & + & -.21 & $-2.05^{*}$ \\
\hline H2a: & Shared beliefs & $\rightarrow$ & Localized social capital & + & -.03 & -0.41 \\
\hline H2b: & Shared beliefs & & $\begin{array}{l}\text { Externalized social } \\
\text { capital }\end{array}$ & + & -.17 & $-2.69 * *$ \\
\hline HЗа: & $\begin{array}{l}\text { Tolerance of incubator } \\
\text { management }\end{array}$ & $\rightarrow$ & Localized social capital & + & .16 & $2.29 *$ \\
\hline H3b: & $\begin{array}{l}\text { Tolerance of incubator } \\
\text { management }\end{array}$ & & $\begin{array}{l}\text { Externalized social } \\
\text { capital }\end{array}$ & + & .09 & 1.29 \\
\hline H4a: & Strategic network participation & $\rightarrow$ & Localized social capital & + & .18 & $2.30 *$ \\
\hline H4b: & Strategic network participation & & $\begin{array}{l}\text { Externalized social } \\
\text { capital }\end{array}$ & + & .61 & $6.16^{* *}$ \\
\hline H5: & Localized social capital & & $\begin{array}{l}\text { Externalized social } \\
\text { capital }\end{array}$ & + & .53 & $5.66^{* *}$ \\
\hline H6: & Resource sharing & $\rightarrow$ & Accelerated learning & + & .73 & $8.00 * *$ \\
\hline H7: & Strategic network participation & $\rightarrow$ & Knowledge assimilation & + & .59 & $3.79 * *$ \\
\hline H8: & Localized social capital & & Accelerated learning & + & .01 & 0.14 \\
\hline H9: & Externalized social capital & $\rightarrow$ & Knowledge assimilation & + & -.29 & $-1.90 *$ \\
\hline H10: & Externalized social capital & & Accelerated learning & + & .17 & $2.47 * *$ \\
\hline H11: & Localized social capital & $\rightarrow$ & Knowledge assimilation & + & .23 & $2.01 *$ \\
\hline
\end{tabular}

${ }^{a}$ Because all hypotheses are directional, we used one-tailed tests: ${ }^{*} p<.05 * * p<.01$ 